\title{
BETA AND ALPHA ELECTROENCEPHALOGRAPHIC ACTIVITY CHANGES AFTER ACUTE EXERCISE
}

\author{
Helena Moraes ${ }^{1}$, Camila Ferreira', Andréa Deslandes', Mauricio Cagy², \\ Fernando Pompeu ${ }^{3}$, Pedro Ribeiro ${ }^{4}$, Roberto Piedade ${ }^{5}$
}

\begin{abstract}
Exercise has been widely related to changes in cortical activation and enhanced brain functioning. Quantitative electroencephalography ( $q E E G$ ) is frequently used to investigate normal and pathological conditions in the brain cortex. Therefore, the aim of the present study was to observe absolute power alterations in beta and alpha frequency bands after a maximal effort exercise. Ten healthy young volunteers were submitted to an eight-minute resting EEG (eyes closed) followed by a maximal exercise test using a mechanical cycle ergometer. Immediately after the exercise, another identical eight-minute EEG was recorded. Log transformation and paired student's t-test compared the pre and post exercise values $(p<0.05)$. Results indicated a significant absolute power increase in beta after exercise at frontal (Fp1, F3 and F4) and central (C4) areas, which might be related to increased cortical activation.
\end{abstract}

KEY WORDS: EEG, exercise, cortical activation

\begin{abstract}
Alterações eletrencefalográficas nas bandas de frequência alfa e beta após exercício de esforço máximo

RESUMO - A atividade física vem sendo relacionada com ativação cortical e melhor funcionamento do cérebro. A eletrencefalografia quantitativa (EEGq) é freqüentemente usada para investigar condições normais e patológicas do córtex cerebral. Sendo assim, o objetivo do presente estudo foi observar alterações na potência absoluta nas bandas de freqüência alfa e beta após um exercício de esforço máximo. Dez voluntários jovens e saudáveis foram submetidos a oito minutos de EEG antes e após um teste de esforço máximo em cicloergômetro. As transformações para o log e o teste t de Student foram utilizados para comparar as respostas eletrencefalográficas entre os momentos pré e pós exercício. Foi observado aumento significativo na potência absoluta de beta após o exercício nos eletrodos frontais (Fp1, F3, F4) e centrais (C4). Este resultado pode estar associado a alterações fisiológicas e ao aumento da ativação cortical.
\end{abstract}

PALAVRAS-CHAVE: EEG, exercício, ativação cortical.

Physical activity has been related to changes in brain functioning and the affective state of an individual. Measurements of quantitative electroencephalography (qEEG) are used to describe functional topographical alterations of cortical activity in fatigue states, e.g., sleep deprivation ${ }^{1,2}$. In this context, it has been suggested that EEG might be especially appopriate for examining the effects of physical fatigue caused by maximal exercise ${ }^{3}$. Changes in the brain electrical activity following exercise might be caused by different factors, such as: changes in body temperature and arousal levels by hypothalamic modulation ${ }^{4,5}$, alterations in cerebral blood flow ${ }^{6,7}$ and individual emotional state ${ }^{8,9}$. Hence, cortical activation following exercise is also related to alterations in EEG frequency bands, such as alpha $(8-13 \mathrm{~Hz})$ and beta $(14-30 \mathrm{~Hz})^{10}$.

Most experiments and literature reviews concerning the effects of acute exercise on brain electrocortical activity measured by electroencephalography (EEG) have been restricted to reports of increased activity in the alpha frequency band ${ }^{11}$. Their common premise has been that increased alpha activity reflects a state of decreased cortical activation, an indication of fatigue, relaxation or decreased anxiety ${ }^{8,12}$. According to a recent review ${ }^{11}$, absolute alpha

\footnotetext{
'Laboratório de Mapeamento Cerebral e Integração Sensório-Motora, Instituto de Psiquiatria (IPUB), Universidade Federal do Rio de Janeiro, Brasil (UFRJ); ${ }^{2}$ COOPE, Universidade Federal do Rio de Janeiro, Brasil (UFRJ); ${ }^{3}$ Departamento de Biociências e Atividade Física, Escola de Educação Física e Desportos (EEFD / UFRJ); ${ }^{4}$ Departamento de Biociências e Atividade Física, Laboratório de Mapeamento Cerebral e Integração Sensório-Motora, Escola de Educação Física e Desportos (EEFD), IPUB / UFRJ, Professor Pesquisador Universidade Castelo Branco (PROCIMH-UCB); ${ }^{5}$ Professor Adjunto Instituto de Psiquiatria, Coordenador Laboratório de Mapeamento Cerebral e Integração Sensório-Motora IPUB / UFRJ.
}

Received 16 August 2006, received in final form 23 January 2007. Accepted 23 March 2007.

Dra. Helena Moraes - Avenida Brasil 11961 / Bl. 07 / Apt 402 - 21012351 Rio de Janeiro RJ - Brasil. 
activity is often increased after exercise when compared to resting levels or to changes after a non exercise control. The cumulative evidence from the few studies that assessed alpha activity in relation to other bands showed no evidence of an effect of exercise that was specific to the alpha band. Moreover, studies that reported changes after exercise in other frequency bands measured concurrently with alpha activity, reported increases in all frequency bands that were similar in size as the increase in alpha absolute activity ${ }^{11}$. Consequently, predominant focus on alpha activity might lead to premature conclusions about the loci and meaning of brain electrocortical responses to exercise ${ }^{12}$.

Therefore, we decided that it would be equally relevant to investigate beta activity associated with acute exercise for several reasons: (1) Some investigations suggest that the increased beta activity observed after exercise is related to higher cortical activation $^{13,14}$; (2) Alterations in the brain blood flow as a consequence of exercise are thought to cause changes in the EEG pattern in the beta range ${ }^{6,7} ;(3)$ the beta frequency band is related to movement, specifically in the frontal and central areas, which are associated with planning and execution of voluntary movements, and, therefore, might be altered by exercise ${ }^{15}$; and (4) the hypothalamic modulation of increased temperature during exercise is thought to influence electrocortical activity in this band ${ }^{4,5}$.

Therefore, the aim of the present study was to observe alterations in alpha and beta activity after a maximal exercise.

\section{METHOD}

Subjects - Ten subjects ( 4 men and 6 women), with ages varying between 21 and 30 years $(26 \pm 5$ for men and $25 \pm 3$ for women), right-handed, non smokers, physically active and healthy subjects were included in this experiment. Subjects answered a simple questionnaire with questions about their general health (anamnesis), lifestyle, drugs/medication and physical activity. The questionnaire also aimed at gathering relevant information such as food intake, hours of sleep and fatigue, resting heart rate, among others. The Edinburgh inventory ${ }^{16}$ was also applied to determine laterality and exclude left-handed individuals form the experiment. As an inclusion criterion, all individuals had to have exercised (cycle ergometer) for more that one year, three times a week. Subjects signed a consent term, which contained protocol information. The Psychiatric Institute Ethics Committee approved the experimental procedure.

Experimental procedures - Electrophysiological recording occurred at two different times: pre and post-exercise. Subjects arrived at the laboratory at 10:00 a.m. and were given 10 minutes to relax before the beginning of the first recording session. Baseline (resting) EEG was recorded for eight minutes in a sound isolated room. During the task, all lights, besides the video monitor, remained turned off to minimized visual stimuli interferences. Individuals sat comfortably in a large chair, in order to reduce muscular artifacts. After the eight minutes of resting EEG recording, subjects were immediately placed on the cycle ergometer. Subjects were then submitted to a progressive workload test (maximal effort test), which ended with voluntary exhaustion. A rate of perceived exaustion (RPE) helped investigators measure each subject's subjective state of fatigue. Once the physical test ended, subjects were again (and immediately) placed on the chair for a second (post exercise) identical EEG session. Exercise protocol is described in greater detail below. Table shows the subjects' anthropometrical and physiological data.

Exercise protocol-Before the beginning of the exercise test, a standing scale measured the subjects' weight and height. A graded cycling test, preceded by a four-minute warm-up, was used while subjects exercised. The maximal effort test was accomplished on a stationary (Monarch ${ }^{\mathrm{TM}}$ Brazil) mechanical cycle ergometer and the work rate increased by 15 to $30 \mathrm{~W} \cdot \mathrm{min}^{-1}$. Each minute, heart rate values and rating of RPE were monitord by a telemetric monitor (Polar ${ }^{\mathrm{TM}}$ Sport Test, Finland) and the 20-point Borg scale ${ }^{17}$, respectively. An audiovisual metrometer was also utilized to control pedal rotation at $60 \mathrm{rpm}$. Maximal effort criteria adopted in this study were: voluntary exhaustion (acoording to the aforementioned method), Borg scale $\geq 18$, heart rate $\geq 90 \%$ maximal heart rate, or incapacity to continue the test. Subjects were verbally encouraged to achieve their maximal level. The duration of the exercise was determined by how long it took for each subject to reach exhaustion. All equipment were calibrated before each test.

Eletroencephalogram recording - Subjects seated comfortably on a large chair in a sound and light-attenuated room, while EEG was collected from 20 monopolar derivations for eight minutes (eyes-closed, alert/resting). Data were collected with eyes closed, to observe electrical activity without external stimuli, thus minimizing possible visual artifacts. After the exercise, the procedure was repeated. To

Table. Subjects data.

\begin{tabular}{lcccccc}
\hline & $\mathrm{N}$ & Age & Weight & Height & Watts max & Heart Rate \\
\hline Women & 6 & $26 \pm 5$ years & $56 \pm 5 \mathrm{~kg}$ & $162 \pm 5 \mathrm{~cm}$ & $191 \pm 38$ & $179 \pm 6$ \\
Men & 4 & $25 \pm 3$ years & $76 \pm 8 \mathrm{~kg}$ & $178 \pm 1 \mathrm{~cm}$ & $285 \pm 51 \mathrm{~W}$ & $176 \pm 7 \mathrm{bpm}$ \\
\hline
\end{tabular}

Mean and standard deviation for the following data: Age, body weight, height, watts maximum, and maximum heart rate. 


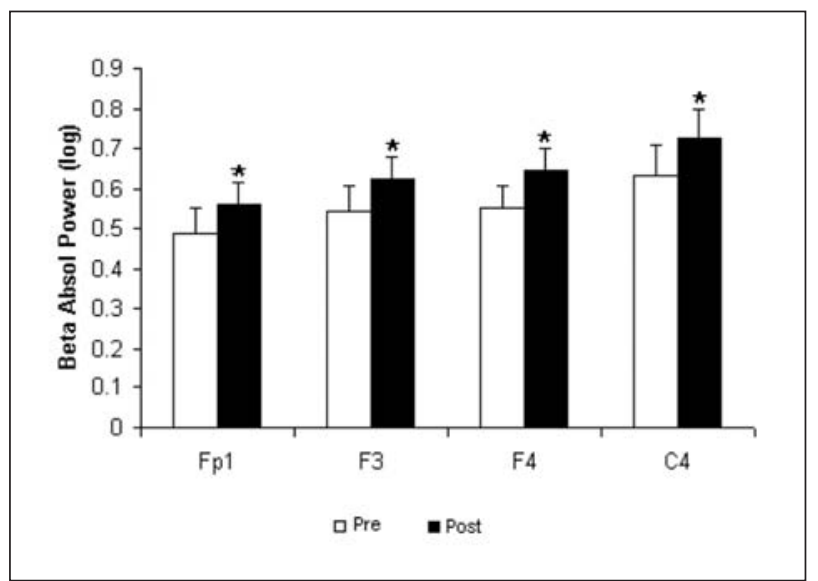

Fig 1. Beta absolute power values (log) across all significant electrodes displaying the differences between the two experimental times. *Significant difference $(p<0.05)$.

avoid the influence of perspiration on the EEG, individuals were dried with a towel. During data acquisition, subjects were instructed to keep their bodies as relaxed as possible. Twenty electrodes were positioned according to International 10 / 20 System, referred to linked earlobes with ground at $\mathrm{FPZ}^{18}$. All electrode impedances were kept below $5 \mathrm{~K}$. The signal was amplified with a gain of 22.000 , analogically filtered between $0.01 \mathrm{~Hz}$ (high-pass) and $100 \mathrm{~Hz}$ (low-pass), and sampled at $240 \mathrm{~Hz}$ using a Braintech-3000 ${ }^{\mathrm{TM}}$ (EMSA-Medical Instruments, Brazil) EEG acquisition system.
The EEG was recorded by means of the software ERP Acquisition (Delphi 5.0 ${ }^{\mathrm{TM}}$, USA), developed at the Brain Mapping and Sensory-Motor Integration Lab. Significance level was set at $\mathrm{p} \leq 0.05$.

Statistical analysis - In order to obtain a normal distribution, absolute power was submitted to a log transformation $\left(\log _{10}\right)$. To compare group means at different experimental moments, i.e., pre and post exercise, a paired t-test was employed. The significance level was set at $p \leq 0.05$.

\section{RESULTS}

A significant beta absolute power increase was observed in the following electrodes: Fp1, F3, F4 e C4 (Fig 1). For a better visualization of the energy shift between the two experimental moments, before and after exercise, a cortical map of beta absolute power alteration is presented (Fig 2). The cortical map was developed with a Matlab $5.3^{\circledR}$ routine (The Mathworks Inc., Massachusetts, USA), by plotting pre and post values, the difference between these two, and $p$ values. Hence, alpha and beta data from the first experimental moment (pre-exercise) were significantly correlated to data from the second experimental moment (post-exercise), as illustrated by Fig 3. However, no differences between moments were found for alpha absolute power.

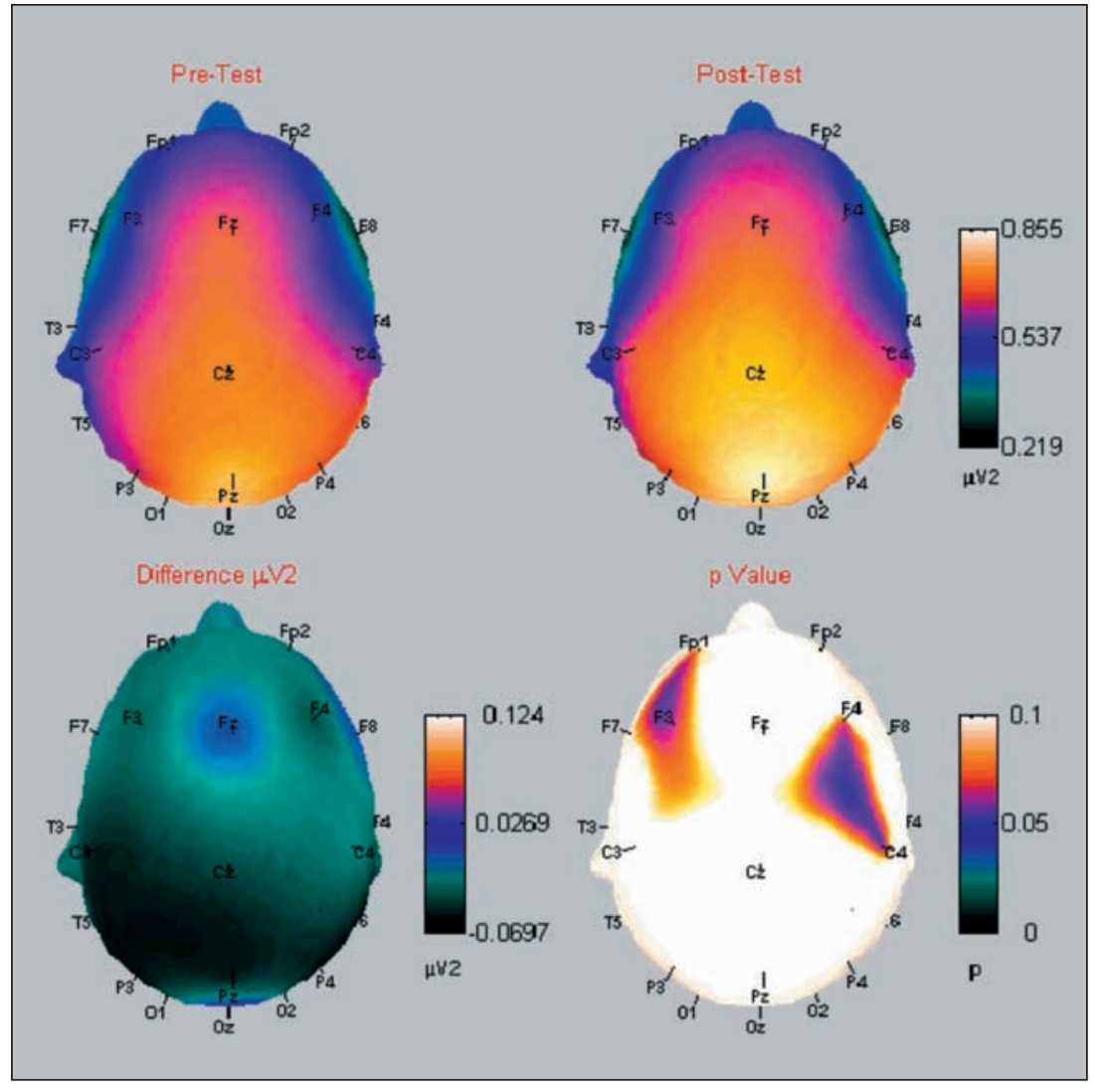

Fig 2. Beta absolute power cortical map showing the energy shift from the pre to the postexercise moment. Note the increased in beta activity at frontal and central sites. Specifically, electrodes Fp1, F3, F4 and C4 showed significant power augmentation. 


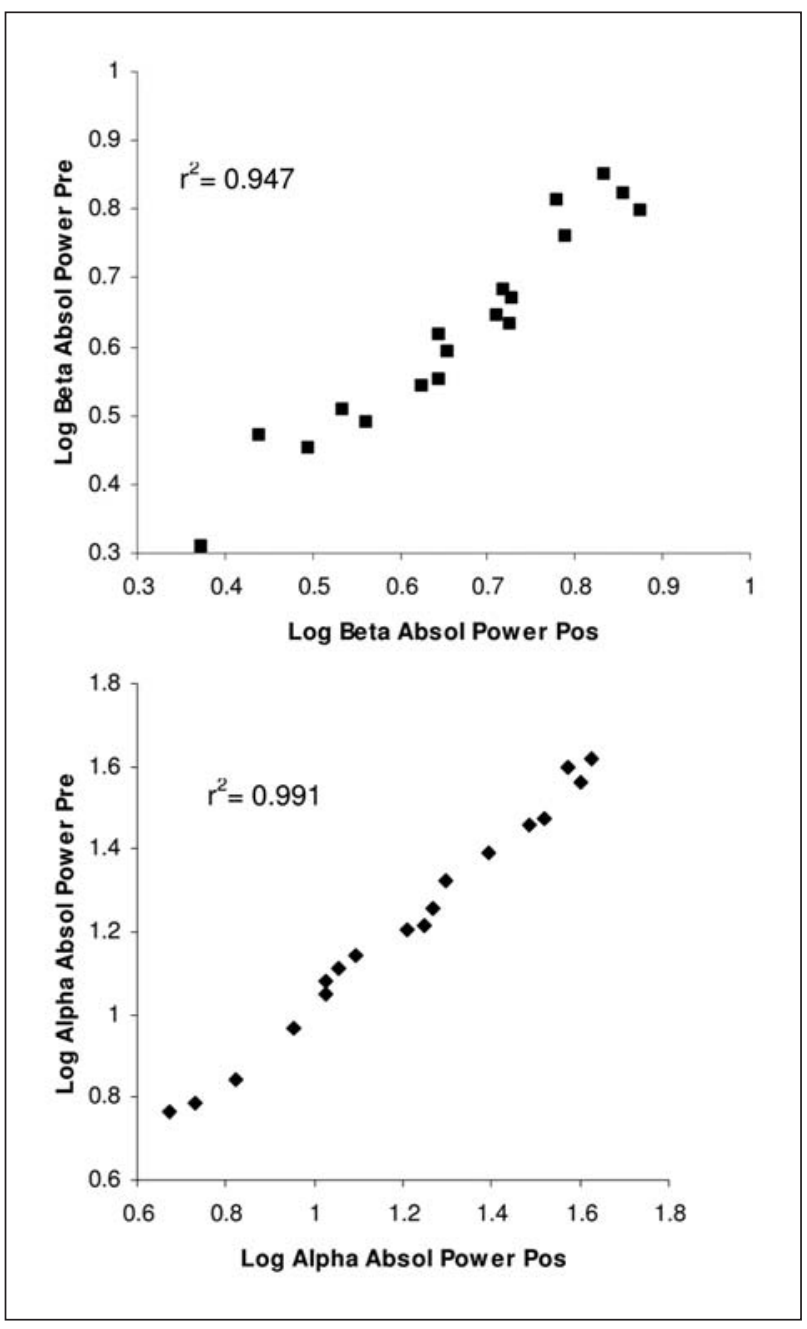

Fig 3. Scatter plot of correlation between log absolute power in the two moments (pre and pos exercise) in alpha and beta bands.

\section{DISCUSSION}

The present study investigated the effects of a maximal effort exercise in the brain electrocortical activity. No significant results were found in the alpha band, althought there was a power increase tendency at frontal sites. On the other hand, the findings showed a significant beta absolute power increase in frontal and central subareas. When pre and post exercise values were compared, a significant power increase was observed in the following electrodes: Fp1, F3, F4 e C4. The increase in beta activity observed here is in agreement with the results of previous studies ${ }^{14,19}$. In recent studies that observed alterations in beta activity $4,5,14,15,20$, authors suggest that the augmentation in beta after exercise is related to greater cortical activation. Increased beta and alpha power are found after a cycle ergometer exercise with continuous intensity at $70 \% \mathrm{VO} \mathrm{max}^{14}$ and progressive workload increase ${ }^{19}$. Kubitz et al. ${ }^{13}$ also observed the same results following exercise, although theses numbers returned to basal values an hour or two after the activity ceased. Youngstedt et al. ${ }^{14}$ have found increased beta activity following acute exercise, although not related to variables such as body temperature and anxiety.

Although exercise causes an increase in brain regional blood flow ${ }^{20}$, this result could be related to other factors. The underlying causes for the influence of exercise on power spectra EEG are however, far from clear, although speculations are made. When a decrease in cerebral blood flow occurs because of anoxia or hypoxia, a decrease in beta (and alpha) activity is observed ${ }^{6}$. If exercise promotes increased cerebral blood flow, an EEG spectral pattern opposite to that is obtained. Therefore, increased circulatory capacity, as a consequence of exercise, might possibly contribute to the observed EEG changes ${ }^{21}$. In addition, beta activity after exercise could be related to an attentional demand and a higher arousal level ${ }^{4}$. In fact, generalized attentional or arousal effects of exercise might influence electrocortical activity in several frequencies and brain loci, leading authors to suggest that brain cortical systems are altered generally in response to the increased metabolic arousal that uniquely accompanies physical activity ${ }^{22}$. Hypothalamic modulation of increased metabolism and temperature during exercise are also thought to influence electrocortical activity; especially in the beta rage $^{4}$. Authors agree that exercise enhances cortical activation, which is represented by increased beta activity ${ }^{13,14}$. Given that exercise increases cortical activation, it probably influences information processing and psychological variables like attention and arousal $^{22,23}$. Hence, we observed an increase in beta power at fronto-central areas, which could be directly related to an excited or urgent/emergency state of mind and increased cortical activation ${ }^{13}$, which might be associated to the increase in other cognitive variables, such as attention. The increase at central sites is expected due to its association to voluntary movements ${ }^{24}$. Although the current literature offers some speculations and hyphoteses, the causes of EEG changes after exercise remain uncertain.

The present study did not find significant results regarding the alpha band. However, other studies that found relevant outcomes in this band analyzed raw absolute power values ${ }^{3}$. Due to the lack of normality in EEG data, they should be previously treated with a log power transformation ${ }^{25,26}$. Such methodological difference might alter the positive outcomes 
in these studies. Besides, only a few investigations in the literature have evaluated the acute effect of exercise in electrocortical activity, making it even harder to compare the results with the current literature.

Exercise promotes alterations in brain activity, which were expressed by the EEG patterns observed in the present study. These electrophysiological changes could represent the rearrangement of different systems as a consequence of exercise. Cognitive, metabolic, physiological, biochemical and even emotional mechanisms might altogether contribute to the expression of the specific electrocortical activity frequently observed after acute exercise. However, the different methodologies employed in other investigations have yielded different electrophysiological results. Our results corroborate the hypothesis that acute exercise causes specifc alterations in brain cortical activity, resulting in increased cortical activation.

\section{REFERENCES}

1. Ferreira C, Deslandes A, Moraes H, et al. The relation between EEG prefrontal asymmetry and subjective feelings of mood following 24 hours of sleep deprivation. Arq Neuropsiquiatr 2006;64:382-387.

2. Ferreira C, Deslandes A, Moraes H, et al. Electroencephalographic changes after one night of sleep deprivation. Arq Neuropsiquiatr 2006; 64:388-393.

3. Mechau D, Mucke M, Weiss M, Liesen H. Effect of increasing running on electroencephalogram in a field test. Eur J Appl Physiol Ocup Physiol 1998;78:340-345.

4. Nielsen B, Nybo L. Cerebral changes during exercise in the heat. Sports Med 2003;33:1-11.

5. Nybo L, Nielsen B. Perceived exertion is associated with an altered brain activity during exercise with progressive hyperthermia. J Appl Physiol 2001;91:2017-2023.

6. Kraaier V, Huffelen AC, Wieneke GH, Worp V, Bär PR. Quantitative EEG changes due to cerebral vasoconstriction. Indomethacin versus hyperventilation-induced reduction in cerebral blood flow in normal subjects. Electroencephalography Clin Neurophysiol 1992;82:208-212.
7. Etnier J, Landers DM. Brain function and exercise: current perspectives. Sports Med 1995;19:81-85.

8. Petruzzello SJ, Landers DM, Hatfield BD, Kubitz KA, Salazar W. A meta-analysis on the anxiety-reducing effects of acute and chronic exercise: outcomes and mechanisms. Sports Med 1991;11:143-182.

9. Hall E, Petruzzello S. Brain activation and mental halth a function of physical activity in older adults. Med Sci Sports Exerc 1997;29:31.

10. Niedermeyer E, Silva F. Electroencephalography basic principles, clinical applications, and related fields. 5.Ed. Philadelphia 2005:167-168.

11. Crabbe JB, Dishman RK. Brain electrocortical activity during and after exercise: a quantitative synthesis. Psychophysiology 2004;41:563-574.

12. Boutcher SH, Landers DM. The effects of vigorous exercise on anxiety, heart rate and alpha activity of runners and nonrunners. Psychophysiology 1988;25:696-702.

13. Kubitz K, Mott A. EEG power spectral densities during and after cycle ergometer exercise. Research Quartely for Exercise and Sport 1996; 67:91-96.

14. Youngstedt S, Dishman R, Cureton K, Peacock L. Does body temperature mediate anxiolytic effects of acute exercise? J Appl Physiol 1993; 74:825-831.

15. Doyle LM, Yarrow K, Brown P. Lateralization of event-related beta desynchronization in the EEG during pre-cued reaction times tasks. Clin Neurophysiol 2005;116:1879-1888.

16. Oldfield RC. The assessment and analysis of handedness: the Edinburgh inventory. Neuropsychologia 1971;9:97-113

17. Borg G. Psychophysical bases of perceived exertion. Med Sci Sports Exerc 1982;14:377-381.

18. Jasper $\mathrm{H}$. The ten twenty electrode system of the International Federation. Electroenceph Clin Neurophysiol 1958;10:371-375.

19. Bailey S, Hall E, Cain J, Miller P, Folger S. Changes in the brain activity during a graded exercise test on a recumbert cycle ergometer (Abstr.). Med Sci Sports Exerc 2004;36(Suppl):S286.

20. Ogoh S, Fadel PJ, Zhang R, et al. Middle cerebral artery flow velocity and pulse pressure during dynamic exercise in humans. Am J Physiol Heart Circ Physiol 2005;288:1526-1531.

21. Lardon M, Polich J. EEG changes from long-term physical exercise. Biol Psychol 1996;44:19-30.

22. Tomporowski P, Ellis N. Effects of exercise on cognitive process: a review. Psychol Bull 1986;99:338-346.

23. Kamijo K, Nishihira Y, Hatta A, et al. Changes in arousal level by differential exercise intensity. Clin Neurophysiol 2004;115:2693-2698.

24. Halliday DM, Conway BA, Farmer SF, Rosenberg JR. Using electroencephalography to study functional coupling between cortical activity and eletromyograms during voluntary contractions in humans. Neursci Lett 1998;241:5-8.

25. Bucci P, Mucci A, Volpe U, Merlotti E, Galderisi S, Maj M. Executive hypercontrol in obsessive-compulsive disorder:electrophysiological and neuropsychological indices. Clin Neurophysiol 2004;115:1340-1348.

26. Gasser T, Bacher P, Mocks J. Transformation towards the normal distribution of broad band spectral parameters of the EEG. Electroencephalography Clin Neurophysiol 1982;53:119-124. 